\title{
Embedded writing instruction in the first year curriculum
}

\author{
Paula Bernaschina \\ Middlesex University, UK \\ Serengul Smith \\ Middlesex University, UK
}

\begin{abstract}
For many university students writing is a struggle and this may be more pronounced for students studying the sciences and technology. They may not foresee the need for good writing skills for their future employability. This case study discusses and critically analyses progress so far with integrating the writing process into the wider employability skills framework devised by the School of Science and Technology (S\&T) at Middlesex University. It discusses areas of the thinking and writing process and highlights issues that have come to the forefront as a result.
\end{abstract}

Keywords: STEM writing; embedding; employability; free-writing; reflective writing.

\section{Introduction}

The role of the Academic Writing and Language (AWL) Coordinator for the School of Science and Technology (S\&T) is to work with the lecturers and to develop and deliver provision to their students. The AWL team is part of the Learner Development Unit (LDU) which is available to all students and offers extracurricular voluntary workshops and tutorials, in addition to the growing embedded work. A variety of workshops are offered throughout the academic year focusing on topics such as essay writing, presentation skills and critical thinking. Confidential one-to-one tutorials are also available which offer students the opportunity to obtain feedback regarding aspects of their learning, especially writing.

Over the last few years the role of the Learner Development Unit within the university has 
been evolving to accommodate changes at the institution. Initially when the LDU was established it was part of Learning Resources, however, in 2010 it became part of the Centre for Learning and Teaching Excellence as a result of restructuring in the university. In this new structure the LDU has become more integrated into the schools and in the development of university strategies regarding student learning.

When the incumbent started the role of AWL coordinator in 2008 , the school was without a designated coordinator due to changes in staffing and a lack of resources. As a result, the staff of the school needed to be made aware of the writing and language support available to its students. This was done systematically through meetings with senior management, lecturers and librarians. Although some staff members were now familiar with the support available, over time it became apparent that only a small number of students in S\&T were taking advantage of the provision available and that a new strategy needed to be put in place to emphasise the importance of good writing and try to improve the students' writing ability.

Embedded writing support was chosen to support writing skills which lecturers often stated needed improvement, including development of ideas, language and grammar. From experience it can be concluded that embedded support is a more efficient and effective way to assist students as those who usually need help tend to be the ones who are least likely to seek assistance. Initially, embedded support consisted of the LDU lecturer working with five lecturers and teaching within their classes infrequently, usually once during the academic year. This meant only the students in those lecturers' classes were receiving some type of extra support. However, there were many more students who could possibly benefit from this assistance.

There is some evidence that science and engineering students in general lack some of the writing skills (King, 2002) needed for success in the workplace. For a variety of reasons these students tend not to be 'readers' or 'writers' and often arrive at university not realising that they will be required to do research which requires academic reading and to write reports and essays to a high academic standard. They also have the misconception that these skills are not necessary in industry. The CBI Higher Education Task Force indicates that employers are least satisfied with new graduates' self-management and communication skills (CBI, 2009). British universities have been increasingly investing in strategies to ensure that their graduates are equipped with relevant knowledge and 
transferable skills to be able to respond to the changing needs of the job market (AGCAS, 2012).

Over the last three years different strategies have been used to find the most appropriate way of supporting our students at Middlesex. According to Wingate (2012), the delivery of writing instruction varies according to the type of higher education institution. Taking into consideration the needs of our students, the following case study explores a strategy undertaken which combines learner support with the development of employability skills.

\section{Rethinking the embedding}

In our work with the students from the school, the librarians and the AWL coordinator had been attempting to make inroads into the modules. In 2010, upon recommendation from some members of senior management in the school and the LDU, a concerted effort was made to focus on the first year core modules for students studying computer science and IT. In theory, the strategy undertaken to embed ourselves into three core modules appeared to be the most comprehensive way of working with the majority of students; however, this plan was flawed. It became apparent some students were receiving these sessions several times over the academic year since some of the programmes require students to take all three of the core modules. As a result, these particular students were becoming 'turned off' and less interested in participating in the repeat sessions.

At the same time, the uptake of tutorials and voluntary workshops for this school was not exemplary, therefore it was important to continue being part of the students' modules. However, the approach needed to be planned differently. In 2011 several meetings with the Academic Dean and the Learning and Teaching Strategy Leader (LTSL) of the school as well as the librarians were initiated. The aim was to target the provision to be more efficient and effective so the whole first year would receive help. It was decided by the LTSL, an academic member of staff in the school, that the embedding would focus on the programmes offered and not individual modules. In addition, the communication skills would focus on those needed in academic and professional environments following the Confederation of British Industry (CBI) guidelines for employability.

The original purpose of the academic writing and language sessions embedded in the 
students' programmes was to enhance their academic literacy and assist them in becoming more successful students. However, with the heightened need for our graduates to be employable, the focus has grown from academic literacy to include 'workplace literacy'. Nevertheless, they should not be considered separate entities but rather a development from one to the other. Although the reading and writing genres can often be different in these two environments, the skills (e.g. developing and structuring writing, critical reading and thinking, etc.) obtained through academic work can be transferred to the workplace. Just as there is a need for good reading and writing skills in an academic environment, this is also almost always the case in employment, especially in the types of employment most university graduates are seeking. The UK Commission's report on employability and skills (2009) emphasises that it is the responsibility of all learning providers to create an institutional culture of employability, make employability part of their core business, and go beyond teaching specific knowledge and vocational skills.

The CBI Employability Guidelines, which include self-management, team working, business and customer awareness, problem solving, communication and literacy, application of numeracy and application of information technology, are 'a set of attributes, skills and knowledge that all labour market participants should possess to ensure they have the capability of being effective in the workplace - to the benefit of themselves, their employer and the wider economy'. These competencies, the CBI believes, make up employability. There is no one approach for embedding employability across a curriculum. There are various methods which may be adopted (York and Knight, 2006), as listed below.

- Employability through a whole curriculum.

- Employability through a core curriculum.

- Employability related modules within a curriculum.

- Work-based or work related learning within a curriculum.

- Work-based or work related learning incorporated as one or more components in a curriculum.

Our approach to embedding employability within the existing programmes in S\&T has utilised two of the above methods. As an initial step, employability related modules have been identified within the whole curriculum by clustering the existing S\&T programmes based on the shared first year modules. Following this, within each cluster, three modules 
have been identified as potential employability related modules. In the next step, The CBI Employability Guidelines were mapped onto sessions provided by the LDU.

In the final step, in order to create a seamless integration of the LDU sessions into the student learning experience, the LTSL worked closely with the coordinator and module leaders to identify those sessions that were most appropriate in terms of the module's practical activities and assessment. Subsequently, the module leaders scheduled these sessions within the module timetable. This means that all students take these sessions as part of their study, and they are also tied into their module content, assessment and practical work.

Therefore, through the embedded work there has been a focus on the employability skills intertwined with the academic skills necessary for the students to do well in their programmes. Noticeably, attentiveness in the sessions has increased when it is made known that these skills are needed for employment. Prior to this some students were uninterested. Embedding learner development work and linking it with employability has shown an increase in students' awareness of the necessity to be responsible for their learning.

\section{The writing}

The first year students have two challenges to face: becoming literate in the language of the university and their area of study; and also beginning to work on the skills and knowledge necessary for their future employment. Although the act of writing is often considered to be a solitary one, in reality this is not the case, especially when the writing takes place in an academic environment. There are many steps that lead up to the moment when words are chosen to express and communicate the ideas and thought processes of the writer. Without these steps there is nothing to write. Therefore it is crucial that university students are aware of the process they need to undertake in order to complete their assignments.

At this stage in our initiative emphasis has been placed on 'free-writing' (Elbow, 1998) and reflective writing (Moon, 2000). These two areas were chosen because first year students are often unfamiliar with them and they are approaches which can assist in the 
composition of academic assignments, and can also be transferred to workplace writing tasks.

Free-writing allows a writer to unload ideas without restrictions often enabling a more fluid writing process. This is an important first step which can ease the beginning of the development of a written essay or report. The technique of free-writing has been integrated into the sessions based on past observations of students working on writing assignments. It is not rare for students to spend a great deal of time attempting to write the perfect sentence or paragraph. However, in the time spent perfecting a small piece of the work, the main ideas could possibly have been written down creating a first draft of the assignment. Of course this draft would most probably need further development as well as editing, however, it would certainly contain many of the ideas needed for the coursework and there would be a sense of accomplishment. Agonising over the structure of the sentence and their choice of words instead of allowing their ideas to flow and getting caught up in the creative process hinders the writing process (Elbow, 1998).

In the initial sessions students were often unfamiliar with free-writing but once it was explained and they were given the opportunity to use it they often found it to be a very positive experience; it allowed many of them to destroy the barrier which often stands in the way of their writing. In a survey presented at the end of one of the modules, $48 \%$ responded to the statement 'I did free-writing to warm up before writing the coursework'.

Reflective thinking and writing have been associated with the 'deep learning' (Biggs, cited King, 2002) in various learning taxonomies (Moon, 2000) and have been seen as important in UK universities over the last decade. Reflective writing helps students to develop and refine the connections between their prior knowledge and newly gained knowledge through their studies. This practice also assists them to make critical connections between theory and practice. For many of our students who are more technical and less academic, the process of writing can be very difficult. When this is combined with reflection it can sometimes become problematic. The act of reflection has an important role in computing and IT and although the students are usually familiar with the idea of reflection they often do not realise the importance of it for their academic and professional lives. A number of writing assignments in their programmes require the students to reflect on decisions or choices made in the process of designing software. These assignments have been constructed to assist the students' development of 
reflective skills which are necessary in the workplace. The decision making needed in industry requires a reflective approach.

In our experience the analytical work needed in a detailed reflective piece is often missing from student work. As a result, during these embedded classes the concept of metacognition is discussed and students are introduced to Kolb's experiential learning theory (Kolb and Kolb, 2005). This initiation into reflective writing assists in some of the second and third year modules in which reflective essays are part of their coursework. These particular students are expected to be able to write reflective essays or reports at all levels and it is a core feature or a component of assessed work in many of the modules; this assists them in developing important skills for the workplace.

As a result of embedding, students from all years in the school are more aware of the LDU and the provision offered to them not only in their content classes but also outside of class time. The figures below show the increase over the years in embedded sessions, voluntary workshops and tutorials. Overall there has been a very substantial increase in the hours provided to the school. The embedded sessions slightly decreased in the past academic year because of the focus on the programmes and not modules.

Table 1. LDU provision for the School of Science and Technology.

\begin{tabular}{|l|c|c|c|}
\hline & $2009-2010$ & $2010-2011$ & $2011-2012$ \\
\hline $\begin{array}{l}\text { Embedded } \\
\text { sessions }\end{array}$ & 25 hours & 143.5 hours & 133 hours \\
\hline $\begin{array}{l}\text { Voluntary } \\
\text { workshops }\end{array}$ & 40 hours & 48 hours & 114 hours \\
\hline Tutorials & 78.5 hours & 129 hours & 233 hours \\
\hline
\end{tabular}

\section{Conclusion}

As our embedding grows and moves beyond the first year students, we believe that responding to the needs of the students to develop context-specific written communication skills will become an increasingly important aspect of our work. This initiative has not only raised student awareness of the existence of the LDU but also of the importance of 
information literacy and academic/professional literacy in their academic work. In addition, the awareness of some of the academics has also been raised. They have requested the embedding initiative to be extended to several of the 2nd and 3rd year modules as well. Moreover, the experience has shown that students are more engaged when the knowledge and skills acquired at university are made relevant to their future careers. The 2012 National Student Survey (NSS) Question 22 asks: 'Looking back on the experience, are there any particularly positive or negative aspects you would like to highlight?' Having received comments in the positive column such as 'English learning support [and] enhancement of employability' has been encouraging and shows the embedding has been effective.

Furthermore, there are several factors besides language which appear to be influencing students' written work and will need to be researched in order for the embedded work to be more successful. The most obvious was that some students were disengaged, not only from the work we were doing with them but from the whole academic process. This was evident in the module attendance rates and more importantly in the retention rate of the school. There are many reasons for this but, based on our impressions of working with these students, the two questions we would now like to address are:

1. Are some of these students disengaged because they commute to the university and as a result do not spend enough time on campus to engage with other students and their lecturers? These students may be missing out on the opportunity to have time to discuss their work and get feedback, to rethink their ideas, and to actively take part in the review process (Kuh et al., 2001).

2. Are some of the students disengaged because they have less experience of academic discourse and practices? Our students arrive at the university from a variety of educational backgrounds and often lack the experience needed to engage fully in university studies (Hockings et al., 2008).

\section{References}

AGCAS (2012) Universities invest in employability. Available at:

http://www.agcas.org.uk/articles/635-Universities-invest-in-employability (Accessed:

28 October 2012). 
CBI (2009) Future fit: Preparing graduates for the world of work, pp. 8. Available at: http://www.cbi.org.uk/media-centre/news-articles/2009/03/future-fit/

Elbow, P. (1998) Writing without teachers. $2^{\text {nd }}$ edn. USA: Oxford University Press.

Hockings, C., Cooke, S., Yamashita, H., McGinty, S. and Bowl, M. (2008) 'Switched off? A study of disengagement among computing students at two universities', Research Papers in Education, 23(2), pp. 191-201.

King, T. (2002) 'Development of student skills in reflective writing', in Goody, A. and Ingram, D. (eds.) Proceedings of the 4th World Conference of the International Consortium for Educational Development. The University of Western Australia, Perth 3-6 July, pp 3. Available at:

http://www.tcd.ie/Nursing_Midwifery/assets/director-staff-edu-dev/pdf/Developmentof-Student-Skills-in-Reflective-Writing-TerryKing.pdf

Kolb, A. and Kolb, D. (2005) 'Learning styles and learning spaces: enhancing experiential learning in higher education', Academy of Management Learning and Education, 4(2), pp. 193-212.

Kuh, G.D., Gonyea, R.M. and Palmer, M. (2001) 'The disengaged commuter student: fact or fiction?', Commuter Perspectives, 27(1), pp. 2-5 [Online]. Available at: http://nsse.iub.edu/pdf/commuter.pdf (Accessed: 12 May 2012).

Moon, J.A. (2000) Reflection in learning and professional development: theory and practice. London: Kogan Page.

UKCES (UK Commission for employment and skills) (2009) The employability challenge - full report. Available at: http://webarchive.nationalarchives.gov.uk/+/http://www.ukces.org.uk/pdf/8080_ UKCES-Employability ChallengeFinal.pdf (Accessed: 28 October 2010).

Wingate, U. (2012) 'Using academic literacies and genre-based models for academic writing instruction: a 'literacy' journey', Journal of English for Academic Purposes, 11(1), pp. 26-37 [Online]. Available at: 
http://webarchive.nationalarchives.gov.uk/+/http://www.ukces.org.uk/pdf/8080UKCES-Employability ChallengeFinal.pdf (Accessed: 5 September 2012).

Yorke, M. and Knight, P. (2006) Embedding employability into the curriculum. York: Higher Education Academy, pp.13-17. Available at: http://www.heacademy.ac.uk/assets/documents/employability/id460 embedding e mployability into the curriculum 338.pdf (Accessed: 28 October 2010).

\section{Author details}

Paula Bernaschina is a Senior Lecturer and the Academic Writing and Language Coordinator in the Learner Development Unit for the School of Science and Technology (S\&T).

Serengul Smith is a Principal Lecturer and the Learning and Teaching Strategy Leader in the School of Science and Technology (S\&T). She is also programme leader of the Information Technology, Multimedia Computing, Information Technology and Networking and Interactive Systems design programmes in S\&T. 